\title{
Interventions for treating asymptomatic impacted wisdom teeth in adolescents and adults (Review)
}

Mettes DTG, Nienhuijs MMEL, van der Sanden WJM, Verdonschot EH, Plasschaert A

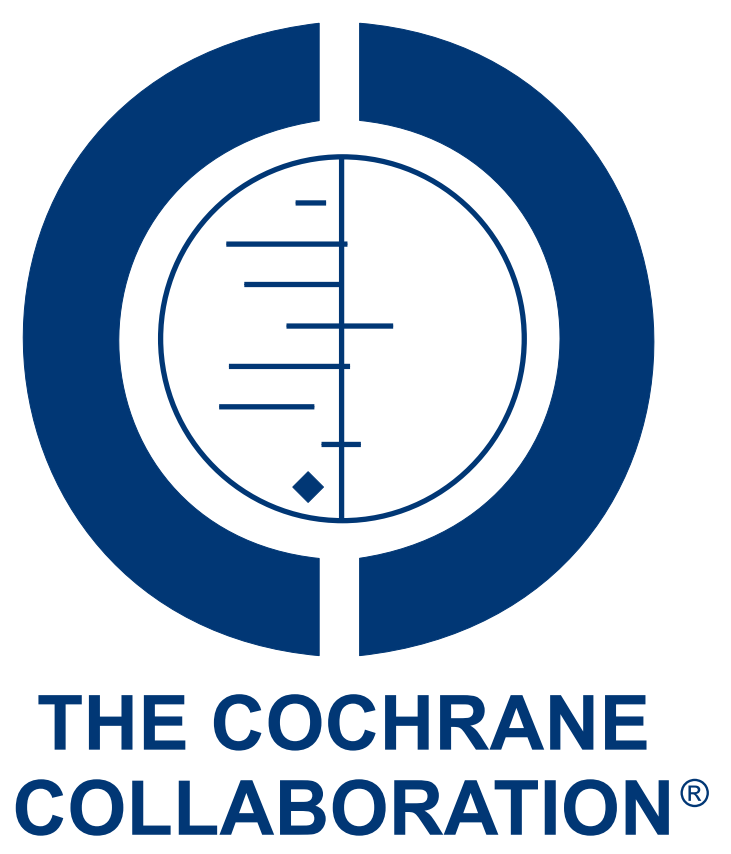

This is a reprint of a Cochrane review, prepared and maintained by The Cochrane Collaboration and published in The Cochrane Library 2008, Issue 4

http://www.thecochranelibrary.com

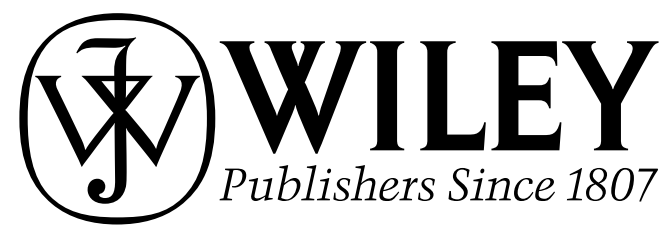

Interventions for treating asymptomatic impacted wisdom teeth in adolescents and adults (Review)

Copyright (C) 2008 The Cochrane Collaboration. Published by John Wiley \& Sons, Ltd. 
TABLE OF CONTENTS

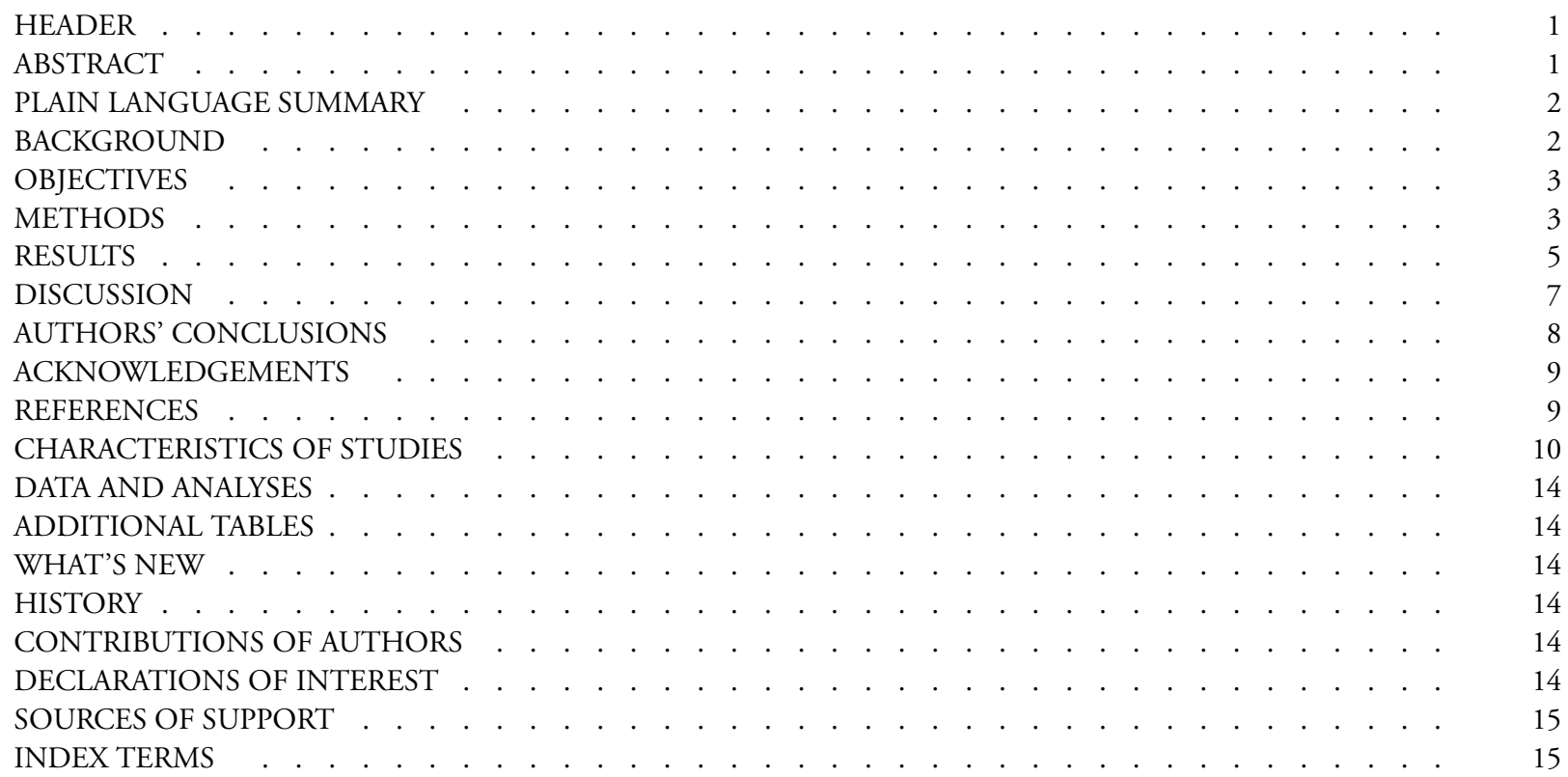

Interventions for treating asymptomatic impacted wisdom teeth in adolescents and adults (Review)

Copyright (C) 2008 The Cochrane Collaboration. Published by John Wiley \& Sons, Ltd. 


\title{
Interventions for treating asymptomatic impacted wisdom teeth in adolescents and adults
}

\author{
Dirk TG Mettes ${ }^{1}$, Marloes MEL Nienhuijs ${ }^{2}$, Wil JM van der Sanden ${ }^{1}$, Emiel H Verdonschot ${ }^{1}$, Alphons Plasschaert ${ }^{1}$ \\ ${ }^{1}$ Preventative and Curative Dentistry, University Medical Centre St Radboud Nijmegen, Nijmegen, Netherlands. ${ }^{2}$ Oral and Maxillo- \\ facial Surgery, University Medical Centre St Radboud Nijmegen, Nijmegen, Netherlands \\ Contact address: Dirk TG Mettes, Preventative and Curative Dentistry, University Medical Centre St Radboud Nijmegen, PO Box \\ 9101, Philips van Leydenlaan 25, Nijmegen, 6500 HB, Netherlands. d.mettes@dent.umcn.nl.
}

Editorial group: Cochrane Oral Health Group.

Publication status and date: Edited (no change to conclusions), published in Issue 4, 2008.

Review content assessed as up-to-date: 6 February 2005.

Citation: Mettes DTG, Nienhuijs MMEL, van der Sanden WJM, Verdonschot EH, Plasschaert A. Interventions for treating asymptomatic impacted wisdom teeth in adolescents and adults. Cochrane Database of Systematic Reviews 2005, Issue 2. Art. No.: CD003879. DOI: 10.1002/14651858.CD003879.pub2.

Copyright (C) 2008 The Cochrane Collaboration. Published by John Wiley \& Sons, Ltd.

\begin{abstract}
A B S T R A C T
Background

The prophylactic removal of asymptomatic impacted wisdom teeth is defined as the (surgical) removal of wisdom teeth in the absence of local disease. Impacted wisdom teeth have been associated with pathological changes, such as inflammation of the gums around the tooth, root resorption, gums- and alveolar bone disease, damage of the adjacent teeth, the development of cysts and tumours. Several other reasons to justify prophylactic removal have also been given. Wisdom teeth do not always fulfil a functional role in the mouth. When surgical removal is carried out in older patients the risk of more postoperative complications, pain and discomfort increases. Nevertheless, in most developed countries the prophylactic removal of trouble-free wisdom teeth, either impacted or fully erupted, has long been considered as 'appropriate care'. Prudent decision-making, with adherence to specified indicators for removal, may reduce the number of surgical procedures by $60 \%$ or more. It has been suggested that watchful monitoring of asymptomatic wisdom teeth may be an appropriate strategy.
\end{abstract}

Objectives

To evaluate the effect of prophylactic removal of asymptomatic impacted wisdom teeth in adolescents and adults compared with the retention of these wisdom teeth.

\section{Search methods}

The following electronic databases were searched: The Cochrane Oral Health Group Trials Register (4 August 2004), the Cochrane Central Register of Controlled Trials (CENTRAL), MEDLINE (1966 to 4 August 2004), PubMed (1966 to 4 August 2004), EMBASE (1974 to 4 August 2004). There was no restriction on language. Key journals were handsearched. An attempt was made to identify ongoing and unpublished trials.

Selection criteria

All randomised or controlled clinical trials (RCTs/CCTs) comparing the effect of prophylactic removal of asymptomatic impacted wisdom teeth with no-treatment (retention).

Interventions for treating asymptomatic impacted wisdom teeth in adolescents and adults (Review)

Copyright (@) 2008 The Cochrane Collaboration. Published by John Wiley \& Sons, Ltd. 


\section{Data collection and analysis}

Assessment of relevance, validity and data extraction were conducted in duplicate and independently by three reviewers. Where uncertainty existed, authors were contacted for additional information about randomisation and withdrawals. A quality assessment of the trials was carried out.

\section{Main results}

Only three trials were identified that satisfied the review selection criteria. Two were completed RCTs and both assessed the influence of prophylactic removal on late incisor crowding in adolescents. One ongoing RCT was identified, but the researchers were unable to provide any data. They intend to publish in the near future and information received will be included in updates. Although both completed trials met the inclusion criteria of the review, regarding participants characteristics, interventions and outcomes assessed, different outcomes measures were assessed which prevented pooling of data.

\section{Authors' conclusions}

No evidence was found to support or refute routine prophylactic removal of asymptomatic impacted wisdom teeth in adults. There is some reliable evidence that suggests that the prophylactic removal of asymptomatic impacted wisdom teeth in adolescents neither reduces nor prevents late incisor crowding.

\section{PLAIN LANGUAGE SUMMARY}

\section{Interventions for treating asymptomatic impacted wisdom teeth in adolescents and adults}

Wisdom teeth, or third molars, generally erupt into the mouth between the ages of 17 to 24 years. However, more than other teeth, wisdom teeth often fail to erupt or erupt only partially. An impacted wisdom tooth is called asymptomatic if the patient does not experience signs or symptoms of pain or discomfort associated with this tooth.

General agreement exists that removal is appropriate in case of symptoms of pain or pathological conditions. Controversial statements exist with regard to the prophylactic removal of asymptomatic or disease-free impacted third molars. This review found no evidence to support or refute routine prophylactic removal of asymptomatic impacted wisdom teeth in adults; no studies of adults met the criteria for inclusion. However, it found some reliable evidence that suggests that the prophylactic removal of impacted third molars in adolescents to reduce or prevent late incisor crowding cannot be justified. Such removal neither reduces or prevents late incisor crowding.

\section{B A C K G R O U N D}

Wisdom teeth, or third molars, generally erupt into the mouth between the ages of 17 and 24 years (Garcia 1989; Hugoson 1988). More than other teeth, wisdom teeth often fail to erupt or erupt only partially (Hugoson 1988). Impaction occurs where complete eruption into a normal functional position is prevented and completion of the root growth is fully established. This can be due to lack of space (in the mouth), obstruction by another tooth, or development in an abnormal position (Venta 1999). A tooth that is completely impacted is entirely covered by soft tissue or covered partially by bone and soft tissue or completely covered by bone. Partial eruption occurs when the tooth is visible in the mouth but has not erupted into a normal functional position (RCS Eng 1997). An impacted wisdom tooth is called trouble-free if the patient does not experience signs or symptoms of pain or discomfort associated with it (Song 1997). The recent literature also refers to descriptions like "disease-free" and "asymptomatic" (Shepherd 1993). Whenever impacted wisdom teeth cause symptoms of pain or pathological changes, such as swelling or ulceration of the gums, the tooth is no longer trouble-free. General agreement exists that removal is then an appropriate treatment decision (Guralnick 1980).

The prophylactic removal of asymptomatic impacted wisdom teeth is defined as the (surgical) removal of wisdom teeth in the absence of local disease. Impacted wisdom teeth have been associated with pathological changes, such as inflammation of the gums around the tooth, root resorption, gums- and alveolar bone 
disease, damage of the adjacent teeth, and the development of cysts or tumours. Several other reasons to justify prophylactic removal have been given. Wisdom teeth do not always fulfil a functional role in the mouth and when surgical removal is carried out on older patients the risk of more postoperative complications, pain and discomfort increases (Brokaw 1991; Mercier 1992; Stavisky 1989; Tate 1994). In most Western countries the prophylactic removal of asymptomatic third molars, either impacted or fully erupted, has long been considered as 'appropriate care' (Brokaw 1991; Tate 1994). However, prophylactic removal of asymptomatic wisdom teeth may lead to considerable postoperative complications (Mercier 1992).

The prevalence of asymptomatic impacted third molars varies widely and is influenced by age, gender and ethnicity (Bradley 1996). Impaction of wisdom teeth in the lower jaw is more common than in the upper jaw (Hugoson 1988). Most of the difficulties following surgical removal, such as postoperative morbidity, pain, discomfort and restricted activity, are related to lower wisdom teeth (SIGN 1999).

The low frequency of pathological changes related to impacted wisdom teeth has been used to promote a more cautious approach (Shepherd 1993; Stephens 1989). Health risks and cost-effectiveness of the prophylactic removal of asymptomatic impacted wisdom teeth should play a more prominent role in the decisionmaking process (Edwards 1999). Moreover, as the costs of surgical removal are significant (Tulloch 1987), removal of asymptomatic impacted wisdom teeth that may remain disease-free indefinitely, produces an unnecessary burden on the healthcare resources (NICE 2000).

There is a large variation among general dental practitioners in their management of asymptomatic impacted lower wisdom teeth (Knutsson 1992). Prudent decision-making, with adherence to specified indicators for removal, may reduce the number of surgical procedures by $60 \%$ or more (Shepherd 1993). It has been suggested that watchful monitoring of asymptomatic wisdom teeth may be an appropriate strategy (Song 2000). The decision-making process, regarding the prophylactic removal of asymptomatic impacted wisdom teeth in the lower jaw, should be based on the best available evidence and combined with clinical experience. In addition, patients' perspectives, values and attitudes should play a prominent role (Bradley 1996).

\section{O B J E C T I V E S}

To evaluate the effectiveness of prophylactic removal of asymptomatic impacted wisdom teeth in adolescents and adults compared with the retention of these wisdom teeth.

The following null hypotheses were tested.
(1) To test the null hypothesis of no difference in clinical effectiveness (in terms of clinical, biological, health related and quality of life outcomes) between surgical removal of asymptomatic impacted wisdom teeth versus retention of these teeth against the alternative hypothesis of a difference.

(2) To test the null hypothesis of no difference in cost-effectiveness of surgical removal of asymptomatic impacted wisdom teeth versus retention of these teeth against the alternative hypothesis of a difference.

\section{METHODS}

\section{Criteria for considering studies for this review}

\section{Types of studies}

All randomised controlled clinical trials (RCTs) and controlled clinical trials (CCTs) comparing the effect of prophylactic removal of asymptomatic impacted wisdom teeth to non-intervention (retention).

\section{Types of participants}

Participants in the studies to be reviewed are individuals (adolescents and adults) with asymptomatic impacted wisdom teeth, and individuals in the same category who underwent prophylactic removal of asymptomatic impacted wisdom teeth. In the original written protocol the intention was to include only studies on adult participants (over 17 years of age). However, no suitable trials were identified. It was therefore decided to expand the remit to include studies on adolescent participants. The justification for this was twofold:

-most people having their wisdom teeth removed are young adults; there is not much clinical difference between adolescents (14 to 17 years of age) and young adults (18 to 25 years of age);

- the existing clinical practice of prophylactic removal of impacted third molars following orthodontic therapy to prevent late incisor crowding.

\section{Types of interventions}

Trials comparing prophylactic removal with retention of asymptomatic impacted wisdom teeth.

\section{Types of outcome measures}

Primary outcomes for hypothesis I 
The Quality of Adjusted Life Years measure associated with retention will include.

\section{Pathological changes}

- Pericoronitis (inflammation of the gum around the crown of a tooth)

- Caries (tooth decay)

- Cysts

- Tumours

- Root resorption

- Dimensional changes in the dental arch (crowding).

\section{Postoperative complications following delayed surgical removal}

- Biological:

- (Temporary) (par)aesthesia (altered sensation) of the tongue and the lip

- Infection of bone and/or surrounding tissues.

- Health related aspects:

- Pain and numbness

- Days off work

- Difficulty in eating and speaking.

The Quality of Adjusted Life Years measure associated with surgical removal will include.

\section{Postoperative complications}

- Biological:

- (Temporary) (par)aesthesia (altered sensation) of the tongue and the lip

- Infection of bone and/or surrounding tissues.

- Health related aspects:

- Pain and numbness

- Days off work

- Difficulty in eating and speaking.

\section{Pathological changes}

- Development of periodontal pockets distally to the second molars

- Dimensional changes in the dental arch.

\section{Search methods for identification of studies}

For the identification of studies included in, or considered for this review, detailed search strategies were developed for each database searched. These were based on the search strategy developed for MEDLINE (OVID), but revised appropriately for each database to take account of differences in controlled vocabulary and syntax rules. The MEDLINE search strategy combined the subject search with phrases one and two of the Cochrane Sensitive Search Strategy for randomised controlled trials (RCTs) (as published in Appendix 5 b.2 in the Cochrane Reviewers' Handbook). The subject search used a combination of controlled vocabulary and free text terms and is published in Appendix 1.

The following databases were searched:

- MEDLINE (OVID) (1960 to 4 August 2004);

- EMBASE (1974 to 4 August 2004);

- PubMed was searched for RCTs using the 'related articles' feature;

- the Cochrane Central Register of Controlled Trials (CENTRAL) (The Cochrane Library 2004, Issue 3);

- the Database of Abstracts of Reviews of Effectiveness (DARE) (4 August 2004);

- the Cochrane Oral Health Group Trials Register (4 August 2004).

\section{Handsearching}

Handsearching of the following journals was conducted by three authors (Dirk Mettes (TM), Marloes Nienhuijs (MN), Wil van der Sanden (WvdS)). A check was made to see which of the journals had already been searched as part of the Oral Health Group's handsearching programme.

A page by page search of the following journals was conducted for eligible studies:

- International Journal of Oral and Maxillofacial Surgery (1972 to 2003);

- Oral Surgery, Oral Medicine and Oral Pathology (1984 to 2003);

- Journal of Oral and Maxillofacial Surgery (1962 to 2003);

- British Journal of Oral and Maxillofacial Surgery (1963 to 2003);

- Journal of Cranio-Maxillofacial Surgery (1973 to 2003).

Reference sections in books on oral surgery and oral pathology were scanned to find relevant studies and proceedings of conferences were looked through in an attempt to identify unpublished studies.

\section{Data collection and analysis}

\section{Primary outcome for hypothesis 2}

- Cost issues of treatment in local currencies.

\section{Study selection}


Two authors (TM, MN) in duplicate, independently and in a nonblinded fashion, assessed the title, keywords, abstracts and/or the materials and methods section of results identified by the search strategy. Relevant articles identified by reference searching were obtained.

All articles selected by the authors were obtained. The articles on which the authors disagree were read in full and a decision to include or exclude was made upon discussion. Persisting disagreement did not occur. The criteria for inclusion were: study design (RCT, CCT), random allocation, comparison of prophylactic removal versus retention, and data on at least one of the selected clinical outcomes as a part of the primary outcome measure: Quality of Adjusted Life Years (health effects on adolescents and adults, economical effects and cost-effectiveness).

\section{Data extraction}

The relevant data were extracted from the included study independently by three authors (TM, MN, WvdS). The following types of data were recorded: year of the publication, date and duration of the study, age of the participants, sample size, numbers of randomised to each group, and data on cost-effectiveness. Comparability of participants, interventions and outcomes at baseline were recorded.

The results were discussed between authors until agreement was obtained. In case of uncertainty the authors would have been contacted for clarification. Should this uncertainty still persist, the data were not been used in the review.

\section{Quality assessment}

The quality assessment of the included trials was undertaken independently and in triplicate by the three authors (TM, MN, WvdS) as part of the data extraction process.

Assigned quality criteria examined were:

(1) Allocation concealment recorded as:

A. Adequate

B. Unclear

C. Inadequate

D. Not used

as described in the Cochrane Reviewers' Handbook, version 4.2.

(2) Treatment blind to outcome assessors, recorded as:

(A) Yes

(B) No

(C) Unclear.

(3) Completeness of follow up (a clear description for withdrawals and drop outs in each treatment group) assessed as:

(A) Yes

(B) No.

After taking into account the additional information provided by the authors of the trials, studies were grouped into the following categories.
(A) Low risk of bias (plausible bias unlikely to seriously alter the results) if all criteria were met.

(B) Moderate risk of bias (plausible bias that raises some doubts about the results) if one or more criteria were partly met (these criteria were categorised as 'partly' in cases where authors had responded that they had made some attempts to conceal the allocation of patients, to blind the assessors or to give an explanation for withdrawals, but these attempts were not judged to be ideal). (C) High risk of bias (plausible bias that seriously weakens confidence in the results) if one or more criteria were not met as described in the Cochrane Reviewers' Handbook, version 4.2.

Further quality assessment was carried out to assess the randomisation procedure, sample size calculations, the definition of exclusion/inclusion criteria, adequate definition of success criteria and comparability of control and treatment groups at the start of the trial.

\section{Data synthesis}

It was planned to undertake sensitivity analyses to examine the effect of randomisation, allocation concealment and blind outcome assessment on the overall estimates of effect.

Data synthesis was only partly carried out due to inadequate reporting of the data in one trial (Lindqvist 1982).

The Cochrane Collaboration statistical guidelines were followed together with calculation of risk ratio values along with $95 \%$ confidence intervals. For continuous outcomes, means and standard deviations were to be used to summarise the data for both groups. Discrepancies in the estimates of treatment effects from the trials were assessed by means of the Cochran's test of heterogeneity. In case of a significant heterogeneity ( $P<0.1$ ), it was planned to reassess the significance of the treatment effects by using a randomeffects model.

\section{R E S U L T S}

\section{Description of studies}

See: Characteristics of included studies; Characteristics of ongoing studies.

Three randomised controlled trials (RCTs) met the review's inclusion criteria, of which one was ongoing.

See Characteristics of included studies and Characteristics of ongoing studies for description of the studies.

\section{Characteristics of the trial setting and investigators}

Of the two included trials (Lindqvist 1982; Harradine 1998), one was conducted in Sweden and the other in the United Kingdom. One trial used a split-mouth design (Lindqvist 1982) and the other 
one a parallel-group design (Harradine 1998). The description of the type of impacted (unerupted) third molars included was different. Both trials included adolescents (14 to 18 years of age) with impacted third molars. Neither trial received any external financial support.

\section{Characteristics of the interventions}

Both studies used the surgical prophylactic removal of asymptomatic impacted third molar as the treatment intervention.

\section{Characteristics of outcome measures}

Lindqvist 1982

Arch length (AL), defined as a straight line between the central fossa of the second lower molar and the incisal cross. The differences between the mean annual change in distances on the extraction side and the change on the control side over the total period of observation was reported by means of the slope values of the individual regression lines for the respective distances. Length of follow up: at least 3 years.

Harradine 1998

(1) Little's Irregularity Index (LII), defined as the sum of the contact points displacements from anatomic contact point to contact point.

(2) Intercanine width (ICW), defined as anatomical distal contact points of the lower canines.

(3) Arch length (AL), defined as the sum of the distances from the mesial contact of the first molar to the midline contact point of the first lower incisor.

These measurements were registered at baseline and follow up. Mean differences with standard deviations and $95 \%$ confidence intervals between two time-points were calculated.

Length of follow up: 5 years, mean length of follow up was $66+1$ -12.6 months.

An ongoing RCT was identified in The Netherlands, conducted in Amsterdam (van de Waal 1999). The research aim of this trial was to compare the effects and costs of prophylactic removal of third molars versus removal as a result of morbidity. Unfortunately, this RCT was discontinued recently for unknown reasons. The data were not available for analysis and contact with the researchers revealed that they still intend to publish the data and experiences in the near future.

See Characteristics of ongoing studies.

\section{Risk of bias in included studies}

Table 1 summarises the quality assessment of the two trials based on an assessment of three criteria: allocation concealment, blinding and completeness of follow up.

\section{Allocation concealment}

The method of allocation concealment was considered adequate for one trial (Harradine 1998) and unclear for the other (Lindqvist 1982).

\section{Blinding}

In both trials it was impossible for patients and operators to be blinded to the intervention, but in one trial (Harradine 1998) the outcome assessor was blinded.

\section{Completeness of follow up}

In both studies withdrawals occurred. In one trial (Harradine 1998) the loss to follow up was described and did not affect the overall results. The split-mouth trial (Lindqvist 1982) did not report any losses to follow up, despite there being some (see 'Table of included studies').

\section{Sample size calculation}

Neither trial reported an a priori sample size calculation.

\section{Randomisation}

In one trial the randomisation method was not reported (Lindqvist 1982) and contact with the authors has not been successful. In the second trial (Harradine 1998) a list of randomly generated numbers was used and qualified as adequate.

\section{Inclusion and exclusion criteria}

Both trials used well described inclusion criteria.

Lindqvist 1982 included only adolescents (mean age 15 years and 6 months, range 13 to 19 ) with unerupted third molars in all quadrants. Half of them had undergone interceptive orthodontic treatment during the mixed dentition and the other half did not receive any orthodontic treatment. The total population $(n=52)$ comprised of 29 females (57\%) at the start. The type of unerupted third molars of participants before inclusion was not described. Harradine 1998 included adolescents (mean age 14 years and 10 months, standard deviation (SD): 16.2 months) who had previously undergone orthodontic treatment. Treatment comprised of active treatment only in the upper jaw and with no treatment or premolar extractions only being carried out in the lower jaw. All participants ( $\mathrm{n}=164 ; 55 \%$ female) had 'crowded' third molars, that is third molars whose long axis and presumed path of eruption was through the adjacent second molar. 


\section{Comparability of control and treatment group at entry}

Gender, age and orthodontic conditions (impacted molars, orthodontic treatment) were mentioned in both trials. In general both groups were comparable in each trial.

More details about comparability of groups at entry would have been useful.

\section{Effects of interventions}

The Lindqvist trial (Lindqvist 1982) was not able to predict which adolescent participants should have benefits or harms after the removal of impacted third molars with regard to late incisor crowding. The length of the arch increased in some participants while in others the arch length decreased during the observation period. On the average, the length of the arch in the whole sample did not change differently on the extraction side compared with the control side of the same patient. However, the length of the arch changed differently on both sides in most of the cases. The extraction side had a more favourable development than the control side in $70 \%$ of the cases. In $30 \%$ of the cases, however, the control side had a more favourable development. The difference varied between $-0.4 \mathrm{~mm}$ and $0.8 \mathrm{~mm}$ (mean change: $0.16 \mathrm{~mm}$ ) over the total observation period of at least 3 years. The relative frequency of positive and negative differences was in general the same in boys and girls. Clinical significant prediction which patients should react favourably to removal of the lower third molar in cases of anticipated crowding was not possible.

The other trial (Harradine 1998) showed no significant differences between both groups. For the data as a whole, there was a mean increase in incisor irregularity of $0.9 \mathrm{~mm}$ (SD: $1.99 \mathrm{~mm}$ ), a decrease in intercanine width of $0.4 \mathrm{~mm}$ (SD: $0.78 \mathrm{~mm}$ ) and a decrease in arch length of $1.5 \mathrm{~mm}$ (SD: $1.76 \mathrm{~mm}$ ).

In participants where third molars were extracted the mean increase in incisor irregularity was $0.80 \mathrm{~mm}$ (SD: $1.23 \mathrm{~mm}$ ) compared with $1.10 \mathrm{~mm}$ (SD: $2.72 \mathrm{~mm})$ where they were not $(\mathrm{P}=$ $0.55)$. For the intercanine width there was no clinical or statistically significant difference. Regarding the arch length, there was a small but statistically highly significant $(P=0.0001)$ decrease in the arch length of the non-extraction group $(2.1 \mathrm{~mm})$ compared with the extraction group $(1.1 \mathrm{~mm})$. This greater decrease in arch length in the non-intervention group raised questions and could not be matched with the lack of statistically significant difference in Little's index between both groups. Re-examination of the casts revealed that 39 of the recalled patients had undergone lower premolar extractions and it was apparent that some of the casts still had some slight residual extraction space at entry, which was not fully closed, despite absence of space being an intended criterion for entry into the study. Further analysis of these 23 cases was made excluding these to examine the possible effects of this factor. The analysis revealed a slight increase in the mean difference for Little's index of irregularity $(1.1 \mathrm{~mm})$ between the non-extraction group compared with the extraction group, but with values still within the $95 \%$ confidence interval ( -0.5 to $2.7 \mathrm{~mm}$ ) and therefore not statistically significant $(P=0.15)$. The disparity in decrease in arch length was reduced to $0.7 \mathrm{~mm}$ mean difference in arch length between the two groups $(\mathrm{P}=0.0035)$. Furthermore the data showed that for the upper jaw no statistical differences between the two groups for any of the measurements existed.

The conclusion drawn from this randomised prospective study was that the removal of impacted third molars to reduce or prevent late incisor crowding cannot be justified.

\section{DISCUSSION}

This Cochrane systematic review focused on randomised and controlled clinical trials on the effectiveness of removing or retaining asymptomatic impacted wisdom teeth in adolescents and adults. However, we identified only two completed studies, which were eligible for inclusion both of which only related to adolescents(i.e. aged 14 to 17 years inclusive).

The conclusion of the Harradine RCT on lower incisor crowding is relevant and related to orthodontic treatment stability, but solely based on one RCT with low risk of bias (grade A, quality assessment). Assessing from a quality of life perspective, the relevance of occurrence of lower incisor crowding to other mentioned pathological changes as possible outcome measures could possibly lead to the conclusion that crowding affects quality of life (it is not life- threatening) to a lesser extent than cysts and tumours do. On the other hand, this phenomenon is frequently seen and changing preferences of younger patients regarding aesthetical aspects of oral health may address more relevance towards a dentition without incisor crowding. Furthermore, neither of the two included studies reviewed, shed any light on patients' perspectives or on cost issues. Research in preferences of patients on these aspects is strongly advocated. No RCTs were identified related to prophylactic removal of impacted third molars in adults.

Nevertheless, the randomised clinical trial is the preferred study design for the assessment of the effectiveness of most health-care interventions. For several reasons, however, it may not be the ideal study design to investigate the justification of prophylactic removal, as opposed to retention, of impacted third molars.

First of all, in such a trial, the onset of disease is measured in the group of subjects in which the third molars are retained. A reasonable evaluation period to measure the prevalence of disease in the retention group would be 20 years, although relevant information may be apparent by 10 years. In the 10 years from the moment of inclusion, at about 20 years of age, most subjects are extremely busy and mobile. Many may move frequently between 20 and 30 years of age so it is extremely difficult for a researcher to keep track of the participants and prevent them from being lost to follow 
up. Also the participants may become increasingly unwilling to be traced, examined or interviewed regularly. Funding of such longterm clinical trials is also assumed to be a substantial barrier to these trials. The fact that two RCTs (only focussed on stability of the dental arch) have been published on the effectiveness of retention and removal of impacted third molars may indicate that researchers anticipate experiencing severe problems regarding the continuity of such a study. Those researchers who endeavoured to start an RCT but failed to reach the endpoint may not have published their experiences, which will have caused publication bias.

Learning from 6 years-researchers' experiences, gathered within a RCT in Amsterdam (which has recently been stopped for unknown reasons), could possibly reveal relevant information about the complexity of a randomised study design in the case of removal or retention of impacted asymptomatic third molars.

Secondly, studies using a primary quality of (adjusted) life outcome measure, based on pathological changes (in case of retention) versus postoperative complications were not identified. The reason we choose this type of primary outcome measure is due to the difficulties of comparing the various outcomes, i.e. the rate of complications after surgical removal versus the incidence of pathological change in case of retention and the rate of complications due to delayed surgical removal (Song 2000). Using quality of life outcome measures is a relatively new research topic in dentistry. Less extensive literature is available, especially on longitudinal trials and measurement of change. Interpretation of change scores continues to be a challenge (Allen 2003). Future research in this area has to deal with the question which oral health related quality of life measure is most appropriate to assign. In the meantime, to promote prudent decision making in daily practice the importance of utility methods by means of analysis studies is acknowledged. They provide more information regarding comparability of different outcomes.

The third molar controversy is still ongoing. Little agreement exists about the appropriateness of prophylactic removal of asymptomatic impacted third molars and the debate yields controversial statements (Flick 1999). The key question in the debate remains: why should impacted wisdom teeth be removed in the absence of symptoms or pathological conditions? If we had the ability to reliably predict future development, prophylactic removal would perhaps be unnecessary (Venta 2000). However, reliable estimates of the onset of pathology related to non-intervention for impacted third molars are modestly unavailable (Venta 2004), due to the widespread practice of routine removal over the past decades. The little information on the prevalence of pathology related to third molars in older patients suggests that the prophylactic removal of all impacted third molars at pre-adulthood may not be justified. Non-intervention outcome studies are rare due to the problems associated with a complex long-term prospective study design (van der Sanden 2002). Explicit record keeping and a systematic reg- istration of the fate and natural course of impacted wisdom teeth in adolescents and adults (where possible collected in national databases) could provide within a relative short period of time clinical data to boost the discussion and elaborate appropriate study designs on this controversial topic.

\section{AUTHORS' CONCLUSIONS}

\section{Implications for practice}

In the absence of more data from randomised controlled trials (RCTs), dental clinicians and oral and maxillofacial surgeons could improve their decision-making by using contemporary evidence and clinical expertise contained in well-designed national clinical practice guidelines (van der Sanden 2003). Existing multi-disciplinary clinical guidelines (NICE 2000; SIGN 1999) should focus on aspects like consistent clinical and radiographical examination and diagnosis in all individuals from the age of about 18 years. The dental clinician, who examines healthy individuals in the course of assigning a recall interval, should be responsible for monitoring third molars in recurrent communication with patients and where there are more complex cases, with the oral and maxillofacial surgeon as a consultant. Special attention should be paid to the onset of pathology, based on explicit terminology and definitions, the monitoring and registration of morbidity and quality of life aspects (i.e. patients' perspective, values and attitudes). Clinicians should make it clear to adult patients with asymptomatic third molars that there is no evidence one way or the other about the benefits or otherwise of removing these molars. The same communication strategy to adolescents and their parents regarding the impact of surgical removal on late lower incisor crowding should be advocated.

\section{Implications for research}

There still is a need for long-term and well-designed prospective studies of asymptomatic impacted third molars. To solve the problem of comparability an overall oral health related outcome measure is advocated. In the absence of better-designed randomised or controlled clinical trials, observational studies (focussed on specific outcomes) could provide the best available evidence to support or refute the effectiveness of the removal of asymptomatic third molars. To gain an insight into the (cost)-effectiveness of retention versus prophylactic removal of asymptomatic impacted third molars existing decision analysis model studies to compare outcomes could be used. Further research in decision analysis models is advocated and patient's preferences and views should be an essential part of this research.

This review concludes that no reliable evidence was found to support or refute routine prophylactic removal of asymptomatic impacted wisdom teeth in adults. There is some reliable evidence that suggest that the prophylactic removal of asymptomatic impacted 
wisdom teeth in adolescents does not reduce or prevent late lower incisor crowding.

\section{ACKNOWLEDGEMENTS}

We would like to thank Sylvia Bickley at the Cochrane Oral Health Group for her guidance and coaching in searching the literature, Jayne Harrison for her support at the editorial base of the Cochrane Oral Health Group, and last but not least Emma Tavender for her reliable and co-ordinating support.

\section{REF E R E N C ES}

\section{References to studies included in this review}

\section{Harradine 1998 \{published data only\}}

Harradine NW, Pearson MH, Toth B. The effect of extraction of third molars on late lower incisor crowding: a randomized controlled trial. British Journal of Orthodontics 1998;25(2):117-22.

\section{Lindqvist 1982 \{published data only\}}

Lindqvist B, Thilander B. Extraction of third molars in cases of anticipated crowding in the lower jaw. American Journal of Orthodontics 1982;81(2):130-9.

\section{References to ongoing studies}

van de Waal 1999 \{published data only (unpublished sought but not used)\}

Effects and costs of prophylactic removal of third molars versus removal according to morbidity.. Ongoing study 1999.

\section{Additional references}

Allen 2003

Allen PF. Assessment of oral health related quality of life. Health and quality of life outcomes. Review 2003; Vol. http://www.hqlo.com/content/I/I/40.

\section{Bradley 1996}

Bradley JG, Zia MJ, Hamilton N. Patient preferences for control in medical decision making: a scenario-based approach. Family Medicine 1996;28(7):496-501.

\section{Brokaw 1991}

Brokaw WC. The third molar question: when and why should we recommend removal?. Virginia Dental Journal $1991 ; 68(4): 18-21$.

\section{Edwards 1999}

Edwards MJ, Brickley MR, Goodey RD, Shepherd JP. The cost, effectiveness and cost-effectiveness of removal and retention of asymptomatic, disease free third molars. British Dental Journal 1999;187(7):380-4.
Flick 1999

Flick WG. The third molar controversy: framing the controversy as a public health policy issue. Journal of Oral and Maxillofacial Surgery 1999;57(4):438-44.

Garcia 1989

Garcia RI, Chauncey HH. The eruption of third molars in adults: a 10-year longitudinal study. Oral Surgery Oral Medicine Oral Pathology 1989;68(1):9-13.

\section{Guralnick 1980}

Guralnick G, Laskin D. NIH consensus development conference for removal of third molars. Journal of Oral Surgery 1980;38:235-6.

\section{Guyatt GH}

Guyatt GH, Sacket DL, Cook DJ. Users' guide to the medical literature. II. How to use an article about therapy or prevention. JAMA 1993;270(21):2598-601.

\section{Hugoson 1988}

Hugoson A, Kugelberg CF. The prevalence of third molars in a Swedish population. An epidemiological study. Community Dental Health 1988;5(2):121-38.

Knutsson 1992

Knutsson K, Brehmer B, Lysell L, Rohlin M. General dental practitioners' evaluation of the need for extraction of asymptomatic mandibular third molars. Community Dentistry and Oral Epidemiology 1992;20(6):347-50.

Mercier 1992

Mercier P, Precious D. Risks and benefits of removal of impacted third molars. International Journal of Oral Maxillofacial Surgery 1992;21(1):17-27.

\section{NICE 2000}

National Institute for Clinical Excellence. NICE technology appraisal guidance, number 1. Guidance on the extraction of wisdom teeth. . London: National Institute for Clinical Excellence, 2000.

RCS Eng 1997

The Faculty of Dental Surgery of the Royal College of Surgeons of England. National Clinical Guidelines 1997. The management of patients with impacted third molar 
(syn.wisdom) teeth. Current clinical practice and parameters of care. London: Royal College of Surgeons of England, 1997.

\section{Shepherd 1993}

Shepherd JP. The third molar epidemic. British Dental Journal 1993;174:85.

\section{SIGN 1999}

Scottish Intercollegiate Guidelines Network. Management of unerupted and impacted third molar teeth. A national clinical guideline. Edinburgh: Scottish Intercollegiate Guidelines Network, 1999.

\section{Song 1997}

Song F, Landes DP, Glenny AM, Sheldon TA. Prophylactic removal of impacted third molars: an assessment of published reviews. British Dental Journal 1997;182(9): 339-46.

\section{Song 2000}

Song F, O'Meara S, Wilson P, Golder S, Kleijnen J. The effectiveness and cost-effectiveness of prophylactic removal of wisdom teeth. Health Technology Assessment 2000;4(15): $1-55$.

\section{Stavisky 1989}

Stavisky E. Clinical justification for the prophylactic removal of impacted third molars. Pennsylvania Dental Journal 1989;56(3):8-9.

\section{Stephens 1989}

Stephens RG, Kogon SL, Reid JA. The unerupted or impacted third molar. A critical appraisal of its pathologic potential. Journal of the Canadian Dental Association 1989; 55(3):201-7.

\section{Tate 1994}

Tate TE. Impactions: observe or treat?. Journal of Californian Dental Association 1994;22(6):59-64.

\section{Tulloch 1987}

Tulloch JF, Antczak-Bouckoms AA. Decision analysis in the evaluation of clinical strategies for the management of mandibular third molars. Journal of Dental Education 1987; 51(11):652-60.

van der Sanden 2002

van der Sanden WJM, Mettes DG, Plasschaert AJ, Grol RP, van 't Hof MA, Knutsson K, Verdonschot EH. Effect of selected literature on dentists' decisions to remove asymptomatic, impacted lower third molars. European Journal of Oral Sciences 2002;110(1):2-7.

van der Sanden 2003

van der Sanden WJM. Clinical practice guidelines in dental care. Studies on development and use. Thesis. Benda, Nijmegen The Netherlands, 2003. [: ISBN 90-9017496-6]

\section{Venta 1999}

Venta I, Turtola L, Ylipaavalniemi P. Change in clinical status of third molars in adults during 12 years of observation. Journal Oral Maxillofacial Surgery 1999;57(4): 386-91.

\section{Venta 2000}

Venta I, Ylipaavalniemi P, Turtola L. Long-term evaluation of estimates of need for third molar removal. Journal of Oral and Maxillofacial Surgery 2000;58(3):288-91.

\section{Venta 2004}

Venta I, Ylipaavalniemi P, Turtola L. Clinical outcome of third molars in adults followed during 18 years. Journal of Oral and Maxillofacial Surgery 2004;62(2):182-5.

* Indicates the major publication for the study 
CHARACTERISTICS OF STUDIES

Characteristics of included studies [ordered by study ID]

Harradine 1998

Methods

Parallel group design. Two treatments groups, random allocation. Patients could not be blinded. Outcome assessor was blinded. $26 \%$ drop out for both study groups combined.

Research aim: to investigate prospectively the effects of early extraction of third molars on late lower incisor crowding.

Outcome measures:

(1) Little's Irregularity Index (LII).

(2) Intercanine width (ICW).

(3) Arch length (AL).

These measurements were registered at baseline and follow up. Differences between two time-points were calculated.

Length of follow up:

5 years, mean length of follow up was $66+/-12.6$ months.

Participants

164 individuals entered the trial (55\% were female), 77 individuals completed the trial ( $58 \%$ were female)

Individuals who had previously undergone orthodontic

treatment, but were no longer wearing orthodontic appliances or retainers. Orthodontic treatment comprised active treatment in the upper arch only with either removable appliances or a single arch fixed appliance, with no treatment or premolar extractions only being carried out in the lower arch.

Individuals with crowded molars (third molars whose long axis and, therefore, presumed path of eruption was through the adjacent second molar).

Baseline characteristics: reported for overall group sample, not per study group.

Age of entry to the trial (mean+/- SD): 14 years 10 months +/- 16.2 months.

Exclusion criteria: Residual premolar extraction space.

Interventions

Group I: Extraction of third molars $(\mathrm{n}=44)$.

Group II: Retention of third molars $(\mathrm{n}=33)$.

Outcomes $\quad$ Mean differences +/- SD change in LII, ICW and AL.

For the upper arch no statistical differences were found between the two groups for the three outcome variables

Notes Sample size calculation: not described.

Analysis (linear modelling) demonstrated no systematic differences between individuals who completed the trial and those who were lost to follow up.

More specified characteristics per study group for comparability at entry would have been appropriate

\section{Risk of bias}

\begin{tabular}{l|ll}
\hline Item & Authors' judgement & Description \\
\hline Allocation concealment? & Yes & A - Adequate \\
\hline
\end{tabular}


Lindqvist 1982

\begin{tabular}{|c|c|c|}
\hline Methods & \multicolumn{2}{|c|}{$\begin{array}{l}\text { Split-mouth design. Aim of the study: to investigate whether third molars can contribute to the occurrence } \\
\text { of crowding. Method of randomisation: not described. Patients could not be blinded. Blinding outcome } \\
\text { assessor not clear. Sample size calculation: not described. Outcome measures: arch length (AL), the dif- } \\
\text { ferences between the mean annual change in distances on the extraction side and the change on those in } \\
\text { the control side over the total period of observation was calculated by means of cephalometric and casts } \\
\text { analyses. Length of follow up: at least three years }\end{array}$} \\
\hline Participants & \multicolumn{2}{|c|}{$\begin{array}{l}\text { Inclusion criteria: patients with unerupted third molars. Total population consisted of } 50 \% \text { participant } \\
\text { who have undergone interceptive orthodontic treatment during the mixed dentition only in the upper jaw } \\
\text { The other } 50 \% \text { received no orthodontic interceptive treatment at all. Exclusion criteria: none reported } \\
\text { Baseline characteristics: for the total study group, relative spacing anterior to the first molar was on averag } \\
\text { zero. Mean age at the time of operation: was } 15.5 \text { years (range } 13 \text { to 19) }\end{array}$} \\
\hline Interventions & \multicolumn{2}{|c|}{$\begin{array}{l}\text { In } 52 \text { participants ( } 29 \text { female) a randomly chosen unerupted third molar was removed at one side, while } \\
\text { the other non-extraction side was used as a control }\end{array}$} \\
\hline Outcomes & \multicolumn{2}{|c|}{$\begin{array}{l}\text { Not described by means of mean changes, standard deviations, P values and confidence intervals. Only } \\
\text { reported as the calculated difference between the annual change on the extraction side and the change } \\
\text { on the control side by means of slope values of the individual regression lines for the respective distances } \\
\text { between reference points and planes }\end{array}$} \\
\hline Notes & \multicolumn{2}{|c|}{$\begin{array}{l}\text { No sample size calculation. Additional interventions in several patients (extraction upper jaw third molars } \\
\text { and second molars). More baseline characteristics per study group at the start would have been useful. No } \\
\text { description of withdrawals. Compensatory removal of the third molar of the same half of the upper jaw } \\
(\mathrm{n}=44) \text { and second molars }(\mathrm{n}=8) \text { were reported and could alter the outcome of the trial }\end{array}$} \\
\hline \multicolumn{3}{|l|}{ Risk of bias } \\
\hline Item & Authors' judgement & Description \\
\hline Allocation concealment? & No & $\mathrm{C}$ - Inadequate \\
\hline
\end{tabular}

\section{Characteristics of ongoing studies [ordered by study ID]}

van de Waal 1999

\begin{tabular}{|c|c|}
\hline Trial name or title & Effects and costs of prophylactic removal of third molars versus removal according to morbidity \\
\hline \multicolumn{2}{|l|}{ Methods } \\
\hline Participants & Healthy participants aged 18 to 30 years with at least one mandibular third molar \\
\hline Interventions & $\begin{array}{l}\text { Group 1: } \\
\text { Prophylactic removal of third molars. } \\
\text { Group 2: } \\
\text { Third molars removed according to morbidity. } \\
\text { The anticipated group size for the completed study are for Group 1: } \mathrm{n}=100\end{array}$ \\
\hline
\end{tabular}


van de Waal 1999 (Continued)

\begin{tabular}{ll} 
& $\begin{array}{l}\text { and for Group 2: } \\
\mathrm{n}=400 .\end{array}$ \\
\hline Outcomes & $\begin{array}{l}\text { Prophylactic removal of third molars is associated with decreased functional health status for about a week, } \\
\text { considerable healthcare costs and production losses in the majority of patients. So far, very few patients } \\
\text { in the watchful waiting group have developed an indication for removal }\end{array}$ \\
\hline Starting date & 1999 \\
\hline Contact information & $\begin{array}{l}\text { Prof. Dr. I. van de Waal, } \\
\text { Free University Amsterdam } \\
\text { Department of Oral and Maxillofacial Surgery. }\end{array}$ \\
\hline Notes & $\begin{array}{l}\text { This trial has been stopped this year (2004). At this moment the reason has not been communicated to the } \\
\text { reviewers }\end{array}$ \\
\hline
\end{tabular}


DATA AND ANALYSES

This review has no analyses.

\section{ADDITIONAL TABLES}

Table 1. Results of quality assessment

\begin{tabular}{llllll}
\hline Study & Allocation concealment & Blinding assessor & Withdrawals & Grade \\
\hline Lindqvist 1982 & No & No & Yes & C \\
\hline Harradine 1998 & Yes & Yes, Single & Yes & A \\
\hline
\end{tabular}

\section{WHAT'S NEW}

Last assessed as up-to-date: 6 February 2005.

\begin{tabular}{lll}
\hline Date & Event & Description \\
\hline 8 August 2008 & Amended & Converted to new review format. \\
\hline
\end{tabular}

\section{H IS T O R Y}

Protocol first published: Issue 1, 2002

Review first published: Issue 2, 2005

\section{CONTRIBUTIONSOFAUTHORS}

Writing the protocol: Dirk Mettes, Emiel Verdonschot.

Literature search and study selection: Dirk Mettes, Marloes Nienhuijs, Wil van der Sanden.

Quality assessment: Dirk Mettes, Marloes Nienhuijs, Wil van der Sanden.

Editing the review: Dirk Mettes, Marloes Nienhuijs, Alphons Plasschaert. 


\section{DECLARATIONS OF INTEREST}

The participating authors declare that they have no financial conflict of interest, nor do they have any associations with industry regarding the subject of this review.

\section{SOURCES OF SUPPORT}

\section{Internal sources}

- Radboud University Medical Centre Nijmegen, Netherlands.

\section{External sources}

- No sources of support supplied

\section{NDEX TERMS}

\section{Medical Subject Headings (MeSH)}

Adolescent; Molar, Third [* surgery]; Randomized Controlled Trials as Topic; Tooth Extraction [ ${ }^{*}$ methods]; Tooth, Impacted [ ${ }^{*}$ surgery]

\section{MeSH check words}

Adult; Humans 